\title{
Investigation of Strength and Migration of Corrugated Cardboard Boxes
}

\author{
Betul Gok' ${ }^{10}$ Duygu Akpinar ${ }^{2}$ \\ ${ }^{1}$ Akdeniz University, Department of Chemistry, Antalya, Turkey \\ ${ }^{2}$ Ankutsan Inc. R\&D Center, Antalya, Turkey
}

\section{ABSTRACT}

$\mathrm{R}$ Corrugated cardboard is a high-performance packaging material designed to protect and present a variety of products from agricultural products to industrial products. Because of this strength of corrugated cardboards are of great importance. In this study, E flute and $\mathrm{BC}$ flute corrugated cardboards were prepared by using different type of paper and their strengths were investigated. For this purpose, weight, thickness measured and edge crush test (ECT) were performed. Results shows that as the paper weight increase, the strength of corrugated cardboard increase. And also, migration tests were done whether corrugated cardboard is appropriate for food contact.

Keywords:

Corrugated cardboard strength; ECT; PCB; Migration; Cobb test; Secondary packaging.
Article History:

Received: 2017/11/28

Accepted: 2020/og/28

Online: $2020 / 09 / 30$

Correspondence to: Betul Gok, Akdeniz University, Chemistry, Antalya, Turkey

E-Mail:betulyitmez@akdeniz.edu.tr Phone: +90 2422497700

Fax: +90 2422497707

\section{INTRODUCTION}

$\mathrm{P}$ aper and paperboard sheet materials obtained from an interwoven lattice of cellulose fibers made of cellulosic material like wood, linen or cotton [1]. The most important application of paper and paperboard is in corrugated paperboard packages.

A corrugated cardboard consisting of a single corrugated layer sandwiched between two liner layers (Fig. 1). This product consists of a combination of the three layers stronger than each layer is individually owned. In addition to single wall, double wall and triple wall corrugated cardboards are also in current use. Double wall corrugated cardboards consist of gluing five layers of paper; one inner, one outer, one intermediate liner paper and two fluted papers and forming a double wall corrugated cardboard.

Corrugated medium part of the cardboard is called as flute (Fig.2). Variations in flute height and number of flutes per unit of length defined as flute type (A, B, C, E)

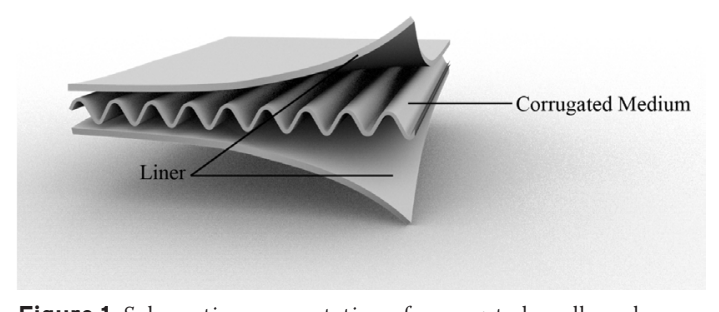

Figure 1. Schematic representation of corrugated cardboard

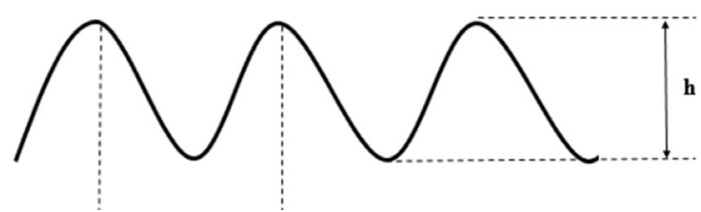

Figure 2. Schematic representation of corrugated medium part of the cardboard (f; wavelength, h; height)

[2]. The take-up factor is a measure of the linear length of the medium per unit length of corrugated cardboard. Table 1 summarize the flute type classification.

Corrugated cardboard is the most widely used type of package for the packaging and distribution of a wide variety of commodities ranging from fruits and vegetables, consumer products, to industrial items. Corrugated cardboards have a high stiffness/weight ratio. Compared to other packaging materials, it delivers relatively high stiffness at a relatively low price [3] [4]. As a packaging material, corrugated cardboards have a lot of advantages over plastic packaging materials. Because it is a kind of environment- friendly packaging material made of reusable paper and water /starch-based glue, which are $100 \%$ recyclable, reusable and biodegradable [5].

It is equally suitable for all the different modes of storage and transport such as shipping by sea or by air. The most important feature of containers made from corrugated boards is to protect the packaged commo- 
Table 1. Corrugated board flute type standards.

\begin{tabular}{ccccc}
\hline Flute Designation & Height $(\mathbf{h})(\mathbf{m m})$ & Wavelength(f) $(\mathbf{m m})$ & Flutes number per Linear Meter & Take-up factor \\
\hline A & $4.0-4.8$ & $8.0-9.5$ & $105-125$ & $1.48-1.53$ \\
B & $2.2-3.0$ & $5.5-8.5$ & $153-181$ & $1.28-1.43$ \\
C & $3.2-4.0$ & $6.8-8.0$ & $125-147$ & $1.42-1.50$ \\
E & $1.0-1.8$ & $3.0-3.5$ & $285-334$ & $1.22-1.29$ \\
\hline
\end{tabular}

dities against all kind of damages during storage and transport. Therefore, the maintenance of strength of cardboard during storing, marketing and distribution of horticultural commodities is needed to take into consideration [6]. The weight, type and properties of the outer, inner and intermediate papers forming the corrugated cardboard are of great importance as they are directly related to the box performance. In addition to the papers used, the type of glue and additives should be chosen appropriately [7]. Paper and board materials that come into contact with foodstuffs must comply with the requirements of the European Framework Regulation (EC) No 1935/2004, which states that materials and products designed to enter foodstuffs do not pose health risks to consumers, affect organoleptic characteristics or alter food composition [8].

In this study we prepared ten different corrugated cardboard for making fresh fruit-vegetable box and pizza box. Then we analyzed the boxes' strength, water absorptivity and conformity with food contact.

\section{MATERIALS AND METHODS}

Starch and $\mathrm{NaOH}$ were purchased from Tate \& Lyle Inc., Koruma Klor Alkali San. ve Tic. Inc., respectively. Borax $\left(\mathrm{Na}_{2} \mathrm{~B}_{4} \mathrm{O}_{7} \cdot 10 \mathrm{H}_{2} \mathrm{O}\right)$ purchased from MTA. Starch Glue prepared according to Stein Hall Method [9]. Different type of papers, Kraft (KR), Neutral Sulfite Semi- Chemical (NC), White Kraft (WKR), White Test Liner (WTL) and Fluting (FL) used for corrugated cardboard production. Kraft papers purchased from 'International Paper Company. VinciLiner (WKR) and NSSC papers purchased from Reno De Medici Group, in Italy.

\section{Preparation of Starch Glue}

For preparation of starch glue, corn starch was used. Starch Glue is prepared according to Stein Hall Method [10] [9]. Stein Hall Method consists of two-phase concept. Primer phase is necessary to give a certain viscosity to glue and keep the viscosity constant.

For this reason, the primer phase is also called as the carrier. This means that the primer phase carries the glue. The secondary phase is the phase of the real glue formation which provides the adhesion of papers. Different resins were added the prescription to improve strengthens the starch stickiness, accelerates the drying and gives firmness. Starch glue viscosity should be stable from preparation to application.

\section{Production of Corrugated Cardboard}

Corrugated cardboards which used for the experiment were produced at Ankutsan A.Ş. production facilities. Corrugated cardboard is formed by gluing the flute layer between two flat liners with starch glue. Double-layer corrugated cardboard consist of three flat liner and two flute liner is also produced for more strength products. Corrugated cardboard manufacturing process begins with the selection of the appropriate type and amount of paper. Production side mainly consist of two parts as wet part and dry part. In the wet production side, paper softened by heat and steam preconditioners takes wave shape by passing through corrugating rolls. After this shaping, the starch-based glue is usually applied to the wave tops and adherence of the flute to pre-heated liner

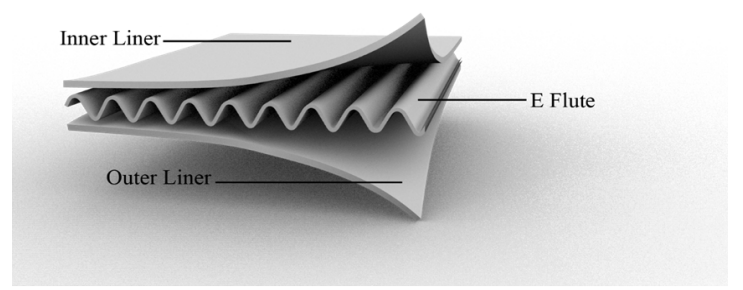

(a)

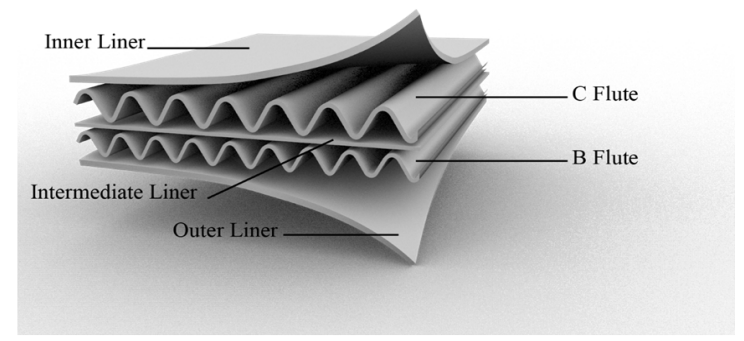

(b)

Figure 3. Illustration of board styles and layers (a) E flute Single Wall (b) BC Flute Double Wall 
paper by pressing is ensured. In the dry production side, after the laminated cardboard sheet is removed from the wet part, the edges are trimmed and sized for the planned box production. Blunt blades pressed on the corrugated cardboard for facilitate box folding. Then the products are stacked on top. In this study, 10 corrugated cardboard samples were prepared with different paper combinations. Two of them are E wave single wall corrugated cardboards used in the production of pizza boxes and are named EF@WTL120 and EF@WTL125. The other eight are $\mathrm{BC}$ wave double wall corrugated cardboards used in the production of fresh fruit and vegetable (FFV) boxes. The paper types and properties used in the preparation of these 10 samples and the names given to the samples are given in Table-2. The nomenclature of the samples was made as "flute type@ changing paper".

\section{Chemical Analysis}

Polychlorobiphenyls (PCBs) analysis of samples were done in Intertek Laboratories according to TS EN ISO 15318 [11] by using ISQ-GC/MS technique. Trace Element analysis of samples was done in Intertek Laboratories and according to NMKL 186 [12] by using ICAP Q ICP-MS technique.

Formaldehyde, chlorine and Pentachloro Phenol (PCP) analysis also was made in İntertek Laboratories according to EN 1541: 2001 [13], TS ISO 5647, Mohr Method and 35 LMBG B 82.02-8 standards, respectively.

\section{Strength Test}

\section{ECT Test}

Edge crush test (ECT) gives information about the strength of corrugated board on vertically positioned corrugations. During these tests it is important that the force applied to the sample is exactly perpendicular. Edge Crush Test (ECT) is carried out according to DIN EN ISO 3037:2013 [14].

Edge Crush Test (ECT) is a true performance test and is directly related to the stacking strength of a carton. ECT is a measure of the edgewise compressive strength of corrugated board. ECT values are of great importance in estimating the quality of corrugated cardboard.

\section{Cobb Tests}

The Cobb test is used to determine the water absorptivity of paper, cardboard and corrugated cardboard. Cobb Test is carried out according to the TAPPIT441 standard [16]. The sample is weighed dry and placed under a cylinder with an inner diameter of about $100 \mathrm{~cm}^{2}$.The cylinder is filled with approximately $100 \mathrm{ml}$ of water. The water is drained after a certain waiting period. The excess water on the sample is wiped with a blotter. The sample is weighed and the amount of water sucked by $1 \mathrm{~m}^{2}$ of the material is calculated (1).

$$
\begin{aligned}
& \text { Weight of water }\left(\frac{g}{m^{2}}\right)=\left[m_{2}-m_{l}\right] \times F \\
& F=\frac{10000}{\text { Surface Area of Sample }}
\end{aligned}
$$

where $m_{2}$ is final weight and $m_{1}$ is dry weight of samples.

\section{RESULTS AND DISCUSSION}

\section{Strength Tests}

ECT test was performed for investigation of paper type and weight effect on corrugated cardboards' strength. In Table 1, when the weight has increased 5 gram of outer

\begin{tabular}{|c|c|c|c|c|c|c|}
\hline \multirow{2}{*}{$\begin{array}{c}\text { Sample Name } \\
\text { EF@WTL120 }\end{array}$} & \multirow{2}{*}{$\begin{array}{c}\text { Flute Type } \\
\text { E }\end{array}$} & \multicolumn{5}{|c|}{ Paper Type and Weight $\left(\mathrm{g} / \mathrm{m}^{2}\right)$} \\
\hline & & WTL 120 & FL 80 & WTL 120 & & \\
\hline EF@WTL125 & $\mathbf{E}$ & WTL 125 & FL 80 & WTL 120 & & \\
\hline BC@NC150 & BC & KR 175 & NC 150 & KR 170 & NC 160 & KR 170 \\
\hline BC@NC160 & BC & KR175 & NC 160 & KR170 & NC 160 & KR 170 \\
\hline BC@FL80-FL75 & BC & KR 100 & FL 80 & FL 75 & FL 100 & KR 100 \\
\hline BC@FL100-FL80 & BC & KR100 & FL100 & FL 80 & FL 100 & KR 100 \\
\hline BC@NC164-KR185 & BC & WKR 225 & NC 164 & KR 140 & NC 170 & KR 185 \\
\hline BC@NC127-KR189 & BC & WKR 225 & NC 127 & KR 140 & NC 150 & KR 189 \\
\hline BC@KR135 & BC & WKR 180 & NC 160 & KR 135 & NC 160 & KR 170 \\
\hline BC@KR170 & BC & WKR 180 & NC 160 & KR 170 & NC 160 & KR 170 \\
\hline
\end{tabular}

Table 2. Corrugated board flute type standards. 
liner paper of E flute corrugated cardboard, strength enhanced \% 15,6. Increasing weight of liner or flute paper led to the enhancement of the CCs strength, which was clear from Table 3, ascending between 7, 77\% to $18,50 \%$. As seen in Fig. 4, when the enhancement in ECT values of the CCs is examined the most significant increase in strength was observed in BC@NC160 and BC@NC127KR189. When the weight of B flute paper of BC@NC150 was increased by $10 \mathrm{~g}$, the strength enhancement was $18.50 \%$ with the highest increase. On the other hand, when the weight of the B flute paper (NC) of BC@NC164KR185 was decreased from 164 to 127 and the weight of inner liner paper (KR) was increased from 185 to 189, there was an enhancement of $18.11 \%$. When the weight of the intermediate liner paper (KR) of BC@KR135 was increased from 135 to 170 (BC@KR170), there was a 7.77\% increase in strength. On the other hand, when the weight of both the intermediate liner paper and the B flute paper of BC@ FL80-FL75 was increased (BC@FL100-FL80), there was an enhancement of $14.35 \%$. Obviously, when the weight of the inner and outer liner papers of corrugated board is increased, there is a significant enhancement in strength. However, increasing the weight of the liner and flute papers has little effect on increasing the strength.

\section{Cobb Tests}

Cobb test were performed for determination of water absorptivity of corrugated cardboard samples. Due to their hygroscopic nature, paper and cardboard tend to hold moisture and water from the surrounding environment. The Cobb test is important because it determines the resistance of paper to water penetration and the amount of water absorbed. A high Cobb value indicates that the material is prone to absorb moisture, while a low value indicates that it is resistant to water penetration and humidity.

Table 3. Effect of the paper type and weight on strength of $E$ flute and $\mathrm{BC}$ corrugated cardboard.

\begin{tabular}{lcc}
\hline \multicolumn{1}{c}{ Sample name } & ECT $(\mathbf{k N} / \mathbf{m})$ & Increase of Strength \% \\
\hline EF@WTL120 & 3,2 & - \\
EF@WTL125 & 3,7 & 15,6 \\
BC@NC150 & 11,61 & - \\
BC@NC160 & 13,76 & 18,50 \\
BC@FL80-FL75 & 4,11 & - \\
BC@FL100-FL80 & 4,70 & 14,35 \\
BC@NC164-KR185 & 12,20 & - \\
BC@NC127-KR189 & 14,41 & 18,11 \\
BC@KR135 & 12,60 & - \\
BC@KR170 & 13,58 & 7,77 \\
\hline
\end{tabular}

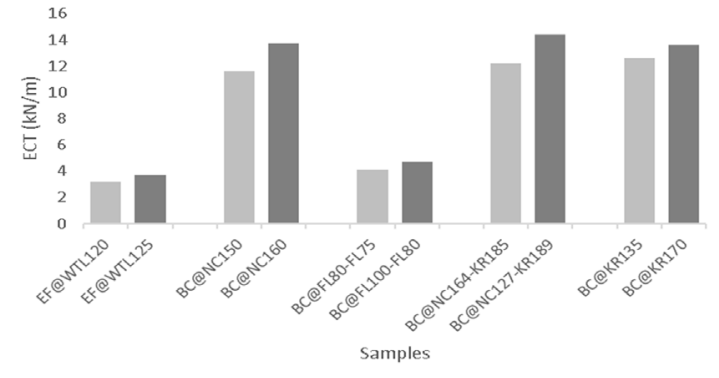

Figure 4. Edgewise compressive strength of corrugated board samples

The Cobb test was performed three times for BC@ NC127-KR189 to obtain the exact value. Table 4 shows the water absorption and Cobb value of BC@NC127-KR189. There is no standard value for corrugated cardboard's Cobb value. We used Kraft paper (Kr) inner surface of the BC@NC127-KR189 that is the surface in contact with water. So, it is expected that the Cobb value of the corrugated cardboard is the same as the Kraft papers used on the inner surface. When the Cobb value of the Kraft paper used is $40 \mathrm{~g} / \mathrm{m}^{2}$, the Cobb value of the corrugated cardboard is $66,35 \mathrm{~g} / \mathrm{m}^{2}$ on average. It can be said that the Cobb value of the corrugated cardboard is higher than the Cobb value of the paper due to the hydrophilic nature of the starch glue used as an adhesive.

\section{ISQ-GC/MS Analysis}

Polychlorinated biphenyls are organic chemicals that are one of the most hazardous environmental pollutants due to their persistence in the environment and their bioaccumulation [17]. PCBs are toxic to all living organisms, including humans, because they tend to accumulate in the lipid tissue. They alter immune functions and cause neurological, developmental, respiratory, and reproductive problems as well as cancer due to estrogenic activity [17].

The chemical formula of PCBs is $\mathrm{C} 12 \mathrm{H} 10-\mathrm{nCln}$, where $\mathrm{n}$ ranges from 1 to 10. There are 209 different PCB congeners, but only 130 of them have been detected in commercial products. Ballschmiter and Zell [18] proposed a numbering system for the PCB congeners which has been adopted by the International Union of Pure and Applied Chemistry (IUPAC) [19].

Table 4. Effect of the paper type and weight on strength of E flute and $\mathrm{BC}$ corrugated cardboard.

\begin{tabular}{ccccc}
\hline $\begin{array}{c}\text { Cobb test } \\
\text { number }\end{array}$ & $\mathbf{m}_{2}(\mathbf{g})$ & $\mathbf{m}_{\mathbf{1}}(\mathbf{g})$ & $\begin{array}{c}\text { Absorbed } \\
\text { Water }(\mathrm{g})\end{array}$ & $\begin{array}{c}\text { Cobb } \\
\left(\mathrm{g} / \mathbf{m}^{2}\right)\end{array}$ \\
\hline 1 & 12,17 & 11,135 & 1,035 & 66,02 \\
2 & 12,195 & 11,080 & 1,115 & 71,02 \\
3 & 12,055 & 11,085 & 0,970 & 62,02 \\
& & & Average & 66,35 \\
\hline
\end{tabular}




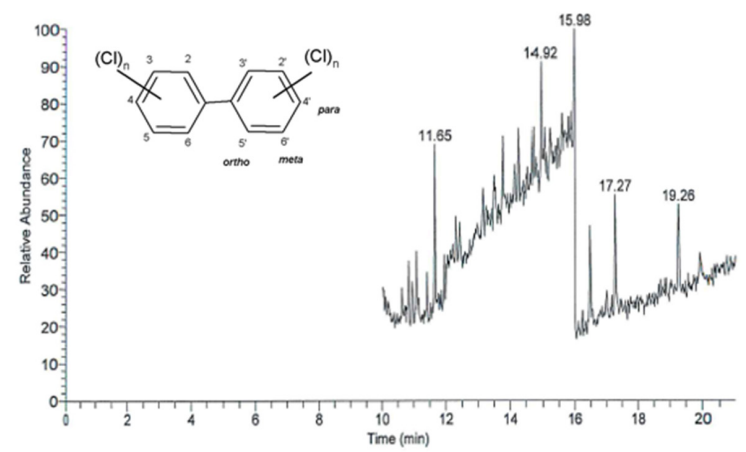

Table 5. PCBs ingredient of corrugated cardboard BC@NC127-KR189

\begin{tabular}{ccc}
\hline RT (min) & Component Name & Amount $\mathbf{m g} / \mathbf{k g}$ \\
\hline 10.84 & PCB_18 & 0,00 \\
11.65 & PCB_28 & 0,00 \\
12.30 & PCB_52 & 0,00 \\
14.25 & PCB_101 & 0,00 \\
16.48 & PCB_138 & 0,00 \\
17.27 & PCB_153 & 0,01 \\
19.26 & PCB_180 & 0,01 \\
\hline
\end{tabular}

5.

Table 6. Interpretation of migration test results according to relevant standards

\begin{tabular}{|c|c|c|c|c|c|}
\hline Analyses name & Method & LOQ & Results mg/kg & Requirement & Interpretation \\
\hline Determination of Overall Migration* & TS EN 118613 & $1 \mathrm{mg} / \mathrm{dm}^{2}$ & $1,9 \mathrm{mg} / \mathrm{dm}^{2}$ & $\leq 10 \mathrm{mg} / \mathrm{dm}^{2}$ & Pass \\
\hline Polichlorbiphenyl (PCB) & TS EN ISO 15318 & $0,5 \mathrm{mg} / \mathrm{kg}$ & Not Detected & $\leq 2 \mathrm{mg} / \mathrm{kg}$ & Pass \\
\hline Formaldehyde & EN 1541: 2001 & $5 \mathrm{mg} / \mathrm{kg}$ & $<5 \mathrm{mg} / \mathrm{kg}$ & $\leq 15 \mathrm{mg} / \mathrm{kg}$ & Pass \\
\hline Pentachloro Phenol (PCP) & 35 LMBG B 82.02-8 & $0,1 \mathrm{~g} / \mathrm{kg}$ & Not Detected & $\leq 0,15 \mathrm{mg} / \mathrm{kg}$ & Pass \\
\hline
\end{tabular}

Table 7. Trace element concentration of BC@NC127-KR189

\begin{tabular}{|c|c|c|c|c|c|}
\hline Analyses name & ${ }_{48} \mathrm{Ti}$ & ${ }_{75} \mathbf{A s}$ & ${ }_{111} \mathrm{Cd}$ & ${ }_{202} \mathrm{Hg}$ & ${ }_{208} \mathrm{~Pb}$ \\
\hline \multirow{3}{*}{ Concentration (ppm) } & 16,1670 & 0,0280 & 0.019 & 0,018 & 0,7510 \\
\hline & 15,6960 & 0,0270 & 0,019 & 0,018 & 0,7420 \\
\hline & 15,6590 & 0,0270 & 0,019 & 0,018 & 0,7360 \\
\hline Concentration average (ppm) & 15,8403 & 0,0273 & 0,019 & 0,018 & 0,7429 \\
\hline
\end{tabular}

PCB content of corrugated cardboard-analyzed according to TS EN ISO 15318 by ISQ-GC/MS analysis technique in order to determine whether the corrugated cardboard BC@NC127-KR189 appropriate for food contact. As shown in Table 4 corrugated cardboard BC@NC127-KR189 has no PCB_18, PCB_28, PCB_52, PCB_101, PCB_138 and 0, 01 $\mathrm{mg} / \mathrm{kg}$ PCB_153, PCB_180.

Pentachloro Phenol is not detected in sample BC@ NC127-KR189 (Table 5). Overall migration from food packaging materials is one of the fundamental requirements according to TS EN 118613 . Overall migration covers all kind of substances which are transferred from food packaging to food irrespective of the nature and the toxicological profile of the substance. Migration test results given in the Table 6 . Overall migration from paper based food packaging materials is limited to $10 \mathrm{mg} / \mathrm{dm}^{2}$ and sample BC@NC127-KR189's overall migration test result is $1,9 \mathrm{mg} / \mathrm{dm}^{2}$, below $10 \mathrm{mg} / \mathrm{dm}^{2}$.

\section{Trace Metal Analysis}

Heavy metal analysis was done in three replicates according to NMKL 186 [20] in Intertek laboratories by using
ICAP Q ICP-MS technique. This method describes the detection of trace elements such as arsenic (As), cadmium $(\mathrm{Cd})$, mercury $(\mathrm{Hg})$ and lead $(\mathrm{Pb})$ at low concentrations in each food. As shown in Table 7 BC@NC127-KR189 contain 15,8403 ppm 48Ti, 0,0273 ppm 75As, 0,019 ppm111 Cd, 0,018 ppm 202Hg and 0,7429 ppm 208Pb.

Restrictions on the trace element content of paper based materials that come into contact with food are determined by the Turkish Food Codex [21]. Lead, chloride and titanium dioxide content of BC@NC127-KR189 below the limitation according to relevant standards (Table 7 and Table 8).

Table 8. Interpretation of trace metal migration results according to relevant standards.

\begin{tabular}{ccccc}
\hline Analyses & $\begin{array}{c}\text { LOQ } \\
\mathbf{m g} / \mathbf{k g}\end{array}$ & $\begin{array}{c}\text { Results } \\
\mathbf{m g} / \mathbf{k g}\end{array}$ & Requirement & Method \\
\hline Hg content & $0.01 \%$ & 0.02 & - & NMKL 186 \\
$\mathrm{Cl}$ content & $0,02 \%$ & N/A & $<=0.2 \%$ & $\begin{array}{c}\text { TS ISO 5647, } \\
\text { Mohr Method }\end{array}$ \\
$\mathrm{Cd}$ content & $0.01 \%$ & 0,02 & - & NMKL 186 \\
Pb content & $0.05 \%$ & 0,74 & $<=20 \mathrm{mg} / \mathrm{kg}$ & NMKL 186 \\
\hline
\end{tabular}




\section{CONCLUSION}

Corrugated cardboard boxes are often used as secondary packaging (carrying box), so the strength of boxes is highly important. In this study, the effect of the paper types and weight used in making corrugated cardboard on the box strength was examined. It can be said that generally increasing the paper quality and weight increases the strength of the box. While inner and outer liner papers of CCs have a significant effect on strength, the intermediate liner and flute papers have a minimal effect

In addition to high strength, it is extremely important that there is no migration from boxes to foods boxes that are in direct contact with food, such as a pizza boxes and fresh fruit and vegetable boxes. We also applied the migration test to the boxes. The results of the analysis show that the corrugated cardboard boxes are suitable for food contact.

\section{ACKNOWLEDGMENTS}

The authors gratefully acknowledge Research and Development Center Unit of Ankutsan Inc (AKS-P-115) for financial support.

\section{References}

1. T. Fadiji, T. Berry, C. J. Coetzee and L. Opara, "Investigating the Mechanical Properties of Paperboard Packaging Material for Handling Fresh Produce Under Different Environmental Conditions: Experimental Analysis and Finite Element Modelling," Journal of Applied Packaging Research, vol. 9, no. 2, pp. 20-34, 2017

2. L. L. Zhao, Evaluation of the Performance of Corrugated Shipping Containers: Virgin Versus Recycled Boards, 1993.

3. B. Steenberg, J. Kubat and L. Rudstrom, Competition In Rigid Packaging Materials, STOCKHOLM: ARBOR PUBLISHING AB 1970.

4. N. Chibani, H. Djidjelli and A. Dufresne, "Study of effect of old corrugated cardboard in properties of polypropylene composites: Study of mechanical properties, thermal behavior, and morphological properties," JOURNAL OF VINYL \& ADDITIVE TECHNOLOGY, pp. 231-238, 2016

5. R. Coles, D. McDowell and M. J. Kirwan, Food Packaging Technology, CRC Press, 2003.

6. D. V. Hung, Y. Nakano, F. Tanaka, D. Hamanaka and T. Uchino, "Preserving the strength of corrugated cardboard under high humidity," Composites Science and Technology, vol. 70, p. $2123-$
2127, 2010.

7. M. Vishnuvarthanan and N. Rajeswari, "Additives for enhancing the drying properties of," Alexandria Engineering Journal, vol. 52, p. 137-140., 2013.

8. R. P. A. T. C. O. T. EUROPEAN, on materials and articles intended to come into contact with food and repealing Directives 80/590/ EEC, 2004.

9. D. Vandevelde, "High dry substance stein hall adhesives and method for preparing high dry substance stein hall adhesives". Patent CA2470618 C, 29 09. 2009.

10. F. O. Ware and W. . S. McDonald, "Process for the production of corrugated paperboard adhesive". Patent US4343654 A, 1081982.

11. International Organization for Standardization, Pulp, paper and board -- Determination of 7 specified polychlorinated biphenyls (PCB),TS EN ISO 15318, 1999.

12. Trace elements - As, Cd, Hg, $\mathrm{Pb}$ and other elements. Determination by ICP-MS after pressure digestion. (NMKL 186), 2007.

13. Paper and board intended to come into contact with foodstuffs. Determination of formaldehyde in an aqueous extract,EN 1541, BSI, 2001.

14. EUROPEAN COMMITTEE FOR STANDARDIZATION, Corrugated fibreboard - Determination of edgewise crush resistance (unwaxed edge method) (ISO 3037:2013), 2013.

15. M. E. Biancolini and C. Brutti, "Numerical and Experimental Investigation of the Strength of Corrugated Board Packages," PACKAGING TECHNOLOGY AND SCIENCE, vol. 16, pp. 47-60, 2003.

16. Technical Association of the Pulp and Paper Industry, Water Absorptiveness of Sized (Non-bibulous) Paper, Paperboard, and Corrugated Fiberboard (Cobb Test), 2013.

17. J. J. Parnell, . J. Park, V. Denef, T. Tsoi, S. Hashsham and J. Quensen, "Coping with Polychlorinated Biphenyl (PCB) Toxicity: Physiological and Genome-Wide Responses of Burkholderia xenovorans LB400 to PCB-Mediated Stress," Applied and Environmental Microbiolgy, vol. 72, no. 10, p. 6607-6614, 2006.

18. K. Ballschmiter and M. Zell, "Analysis of Polychlorinated Biphenyls (PCB) by Glass Capillary Gas Chromatography," Fresenius' Zeitschrift für Analytische Chemie, no. 302, pp. 20-31, 1980.

19. World Health Organization, "Polychlorinated biphenyls(PCBs)," in Air Quality Guidelines For Europe-Second Edition, Denmark, WHO Regional Publications, 2000, pp. 97-101.

20. "www.nmkl.org," [Online]. Available: http://www.nmkl.org/index. php/en/webshop/item/tungmetaller-as-cd-hg-og-pb-bestemmelsemed-icp-ms-etter-syreoppslutning-under-trykk-nmkl-186-2007. [Accessed 228 2017].

21. "resmigazete.gov.tr," 1912 2011. [Online]. Available: http://www. resmigazete.gov.tr/eskiler/2011/12/20111229M3-9.htm. [Accessed 228 2017].

22. EUROPEAN COMMITTEE FOR STANDARDIZATION, Paper and board - Determination of water absorptiveness - Cobb Method, Turkish Standards Institute, 2014 